\title{
III. DIE PHASE DER VERHANDLUNGEN EINE DOPPELSTRATEGIE (24.-28. JULI)
}

\section{Bemühungen um ein politisches Arrangement}

Nachdem am 24. Juli das Ultimatum der Habsburgermonarchie in Europa bekannt geworden war, schlug Frankreich einen außenpolitischen Kurs ein, der unverkennbar die Merkmale einer Doppelstrategie trug. In ihrem Rahmen ließ sich sowohl eine nach den einzelnen Entscheidungsträgern unterschiedlich abgestufte Bereitschaft zu einem friedlichen Ausgleich unter den Mächten als auch der Versuch erkennen, Frankreich in eine möglichst günstige Ausgangsposition für den Großen Krieg zu manövrieren.

Dem Unterfangen, das Deutsche Reich und die Habsburgermonarchie ins Unrecht zu setzen, um im Fall einer Eskalation der Krise für die militärische Intervention Großbritanniens und die Einheit der französischen Nation zu sorgen, galten am 24./25. Juli die ersten Schritte Frankreichs. Ihm entsprach der Rat, den Philippe Berthelot, der in der Spanne zwischen dem 18. Juni und dem 29. Juli die politische Direktion des französischen Außenministeriums leitete, am 24. Juli dem serbischen Botschafter erteilte. Er legte Serbien nahe, das Ultimatum nicht a limine abzulehnen, sondern sich auf die Forderungen einzulassen, die mit seiner Souveränität und Ehre in Einklang standen ${ }^{1}$. Sollte die Habsburgermonarchie eine Antwort als unzureichend verwerfen, die ihren Forderungen entgegenkam, und sich nicht dazu bereit finden, auf einer solchen Grundlage in Verhandlungen einzutreten, dann gestand sie öffentlich ein, daß ihr Ultimatum in der Absicht entworfen worden war, eine militärische Auseinandersetzung einzuleiten, und hatte sich geschickt ins Unrecht setzen lassen.

In ebendiese Richtung führte auch der Versuch, durch eine gemeinschaftliche Intervention der Mächte einen zeitlichen Aufschub für die serbische Antwort durchzusetzen ${ }^{2}$. Als die französische Führung an Bord der "France« am 25. Juli von der Absicht Rußlands erfuhr, die Habsburgermonarchie um eine Verlängerung der Frist zu bitten, veranlaßte Poincaré seinen Außenminister sofort, diese Forderung zu unterstützen ${ }^{3}$. Doch der französi-

$1 \mathrm{Vgl}$. Bienvenu-Martin an Viviani, 24. 7. 1914, in: DDF 3, 11, 15. Vgl. auch Szécsen an Berchtold, 24. 7. 1914, in: ÖUA 8, 10608 und Schoen an AA, 24. 7. 1914, in: DD 1, 154. $\mathrm{Vgl}$. ferner Berthelots Einlassung gegenüber Victor Margueritte, die überliefert wird bei AlBERTINI, Origins, Bd. II, S. 362.

2 Vgl. Paléologue an Bienvenu-Martin, 25. 7. 1914, in: DDF 3, 11, 34. Vgl. ferner Note du Département, 25. 7. 1914, in: DDF 3, 11, 35 und Bienvenu-Martin an Paul Cambon, Jules Cambon, Dumaine, Paléologue, Barrière, Thiebaul und Bapst, 25. 7. 1914, in: DDF 3, 11, 38 .

3 Vgl. Notes journalières, in: NL Poincaré, BNF, Nafr. 16027, fol. 115 (Eintrag vom 25. 7. 1914). 
sche Präsident erblickte darin kein geeignetes Mittel, um eine Vermittlung einzuleiten: Il est peu probable, notierte er unter dem Datum des 25. Juli 1914 in seinem Tagebuch, que l'Allemagne accepte de faire cette démarche. Mais, si elle la refuse, elle se mettra dans une situation très fausse en prenant à son compte, vis-à-vis du monde, les violences de l'Autriche [sic] $]^{4}$.

In seiner Einschätzung der deutschen Absichten ging Poincaré nicht fehl, denn die Reichsleitung dachte nicht daran, die Forderung nach einem zeitlichen Aufschub zu unterstützen. Im Vorfeld des 23. Juli hatte das Deutsche Reich seinen Bündnispartner zu einem raschen fait accompli gedrängt und nunmehr forderte es, um einem Interventionsversuch der Mächte die Grundlage zu nehmen, Österreich-Ungarn zu einer umgehenden Kriegserklärung an Serbien, hingegen Frankreich, Rußland und Großbritannien zu einer Lokalisierung des Konfliktes auf ${ }^{5}$.

Nachdem der deutsche Botschafter in Paris am 24. Juli im französischen Außenministerium das Ultimatum der Habsburgermonarchie gerechtfertigt und zur Lokalisierung des Konfliktes gemahnt hatte ${ }^{6}$, unternahm er an den folgenden Tagen mehrfach den Versuch, Frankreich im Sinne der deutschen Forderung zu einer Intervention in Petersburg zu veranlassen und damit die Mächte der französisch-russischen Allianz auseinander zu manövrieren. Für den Erfolg eines solchen Unterfangens lagen die Dinge am Quai d'Orsay zunächst nicht ungünstig?.

Als der Botschafter der Habsburgermonarchie dem Justizminister, der bis zur Rückkehr der französischen Führung nach Paris am 29. Juli das Außenministerium kommissarisch leitete, das Ultimatum zur Kenntnis brachte, hatte Bienvenu-Martin Verständnis für das Anliegen Österreich-Ungarns gezeigt, die Hintergründe des Attentates umfassend aufzuklären und sich gegen eine auf die territoriale Dekomposition der Monarchie gerichtete serbische Propaganda zu schützen ${ }^{8}$. In seiner ersten Unterredung mit dem deutschen Botschafter hatte er diesem sogar vorsichtig zu verstehen gegeben, daß er die Forderung nach Garantien für das künftige Handeln Serbiens als legitim erachtete, doch hatte er noch die Frage unbeantwortet gelassen, welche Formen diese Garantien annehmen konnten'. Der Justizminister war in den

4 Zit. ibid.

5 Vgl. Szögyény an Berchtold, 25. 7. 1914, in: ÖUA 8, 10656. Vgl. ferner Tschirschky an AA, 26. 7. 1914, in: DD 1, 213. Zur Forderung nach einer Lokalisierung des Konfliktes vgl. Bethmann Hollweg an Pourtalès, Schoen und Lichnowsky, 21. 7. 1914, in: DD 1, 100.

6 Vgl. Schoen an AA, 24. 7. 1914, in: DD 1, 154.

7 Vgl. zum folgenden insbesondere AlBERTINI, Origins, Bd. II, S. 322-329. Die älteren Darstellungen beruhen noch auf den gefälschten Dokumenten des französischen Farbbuches, die die erste Reaktion des französischen Justizministers auf das Ultimatum gründlich verzeichnen. Vgl. RENOUVIN, Les origines immédiates, S.94-98 und SCHMITT, Coming of War, Bd. II, S. 11-15.

$8 \mathrm{Vgl.} \mathrm{Szécsen} \mathrm{an} \mathrm{Berchtold,} \mathrm{24.} \mathrm{7.} \mathrm{1914,} \mathrm{in:} \mathrm{ÖUA} \mathrm{8,} 10606$.

9 Vgl. Bienvenu-Martin an Thiébault, Boppe, Paul Cambon, Paléologue, Jules Cam- 
Dingen der äußeren Politik unerfahren, und für seine Unterredungen mit den Botschaftern der Habsburgermonarchie und des Deutschen Reiches besaß er zunächst keine Instruktionen. Seine Einlassungen waren dementsprechend von vorsichtiger Zurückhaltung geprägt, doch aus ihnen sprach eine unverkennbare Sympathie für Österreich-Ungarn, die das Unterfangen des deutschen Botschafters begünstigen mußte. Dieser versuchte, umgehend die Gunst der Stunde zu nutzen, und forderte, nachdem die Habsburgermonarchie die Antwort Serbiens auf das Ultimatum als unzureichend verworfen und daraufhin die Beziehungen zu ihrem südöstlichen Nachbarn abgebrochen hatte, den Justizminister am 26. Juli auf, im Sinne einer Lokalisierung des Konfliktes auf das Zarenreich einzuwirken ${ }^{10}$.

Doch zu diesem Zeitpunkt stand Bienvenu-Martin bereits unter dem Einfluß Berthelots, hatte sich dessen Einschätzung der Lage und dessen Außenpolitik zu eigen gemacht ${ }^{11}$. Berthelot, der die erste Unterredung zwischen dem Justizminister und dem deutschen Botschafter am 24. Juli mit angehört hatte, war aufgrund der Einlassungen Schoens zu dem Urteil gelangt, daß das Deutsche Reich versuchen werde, Frankreich durch eine kaum verhüllte militärische Drohung in einen Gegensatz zu seinem russischen Bündnispartner zu bringen, um durch einen österreichischen Krieg gegen Serbien einen außerordentlichen Prestigeerfolg zu erzielen. Obwohl er der Ansicht war, daß das Deutsche Reich im Fall eines Scheiterns seiner Konzeption den Großen Krieg führen werde, versuchte er umgehend, die Absichten des Botschafters zu durchkreuzen ${ }^{12}$.

Als der deutsche Botschafter am 26. Juli mit der Forderung am Quai d'Orsay vorstellig wurde, daß Frankreich auf seinen Bündnispartner im Sinne einer Lokalisierung des Konfliktes einwirken solle, behandelte der Justizminister dieses Ansinnen ablehnend, indem er sich auf fehlende Instruktionen

bon, Dumaine und Barrère, 24. 7. 1914, in: DDF 3, 11, 20. Vgl. auch Schoen an AA, 24. 7. 1914, in: DD 1, 154.

$10 \mathrm{Vgl}$. Note du Ministre par intérim, 26. 7. 1914, in: DDF 3, 11, 81. Vgl. auch Schoen an AA, 26. 7. 1914, in: DD 1, 235.

11 Je savais que ce baut fonctionnaire avait une grande expérience des affaires extérieures et je dois reconnaître, gestand Bienvenu-Martin in seinen Erinnerungen, que ses avis éclairés $m$ 'aidèrent beaucoup. Zit. BIENVENU-MARTIN, Mon intérim, S. 641. Vgl. auch Bertie an Tyrell, 27. 7. 1914, in: NL Bertie, PRO, FO 800/166, fol. 84: M. Berthelot gave Granville to understand that $M$. Bienvenu-Martin counted for nothing in Foreign Affairs and that be (M. Bertbelot) was the person [Hervorhebung im Original, St. S.]. $12 \mathrm{Vgl}$. Berthelots Außerungen gegenüber dem Geschäftsträger der russischen Botschaft. Vgl. Sewastopulo an Sasonow, 26. 7. 1914, in: IB I/5 93. Vgl. auch BARRÉ, Philippe Berthelot, S. 271-273 und HAYNE, French Foreign Office, S. 280f. Auch der Unterstaatssekretär im Außenministerium teilte diese Auffassung Berthelots. In den seiner Ehefrau diktierten Aufzeichnungen über die Julikrise heißt es: Tout le jeu de l'Allemagne tendait à nous faire faire une fausse manceuvre qui pût nous disjoindre de la Russie. Zit. Abel FERRY, Les carnets secrets d'Abel Ferry, Paris 1957, S. 22. Dieses nachträgliche Urteil stimmt mit einer Notiz vom 27. Juli 1914 im Nachlaß Ferrys überein. Vgl. NL Ferry, MAE, PA-AP 181/1, fol. 3 . 
berief. In seiner Unterredung mit Schoen vertrat er zunächst die Ansicht, daß Frankreich vielleicht an einer gemeinschaftlichen Vermittlung der Mächte zwischen Österreich-Ungarn und dem Zarenreich mitwirken könne, doch letztlich verwarf er auch einen solchen Gedanken ${ }^{13}$. Eine sehr viel deutlichere Sprache sollte dann Berthelot kurze Zeit später gegenüber dem Botschafter führen. Als der deutsche Botschafter nach seiner Unterredung mit dem Justizminister an ihn mit der Forderung herantrat, ein Kommunique des Inhalts zu publizieren, [que] L'Ambassadeur d'Allemagne et le Ministre des Affaires étrangères ont eu [...] un nouvel entretien au cours duquel ils ont examiné dans l'esprit le plus amical et dans un sentiment de solidarité pacifique les moyens qui pourraient être employés pour maintenir la paix générale ${ }^{14}$, widersetzte er sich diesem Ansinnen. Das Kommunique, das dann im Anschluß an ein für den deutschen Botschafter ersichtlich enttäuschendes und zuweilen sehr unfreundlich gehaltenes Gespräch der französischen Presse übergeben wurde, konstatierte ausschließlich: [que] L'Ambassadeur d'Allemagne et le Président $d u$ Conseil par intérim ont eu un nouvel entretien au cours duquel ils ont recherché les moyens d'action des Puissances pour le maintien de la paix ${ }^{15}$. Der Vergleich der Fassungen zeigt, daß Berthelot weder konstatiert wissen wollte, daß der Geist der gemeinsamen Unterredung vom 26. Juli »freundlich« gewesen, noch daß in ihr eine deutsch-französische »Solidarität « zum Ausdruck gebracht worden sei, die nach Lage der Dinge einer Distanzierung vom Bündnispartner gleichkommen mußte und das Zarenreich im Fall einer Eskalation der Krise mit dem Odium der Schuld belasten würde ${ }^{16}$.

Doch die ungeschickte Einlassung Bienvenu-Martins vom 26. Juli, daß Frankreich vielleicht in einem Konflikt zwischen dem Zarenreich und der Habsburgermonarchie vermitteln könne, ließ eine Reaktion Rußlands aufblitzen, auf die das Deutsche Reich spekuliert hatte. Als der russische Außenminister durch ein Telegramm des Geschäftsträgers der zarischen Botschaft von diesem Gedanken Bienvenu-Martins erfuhr, telegraphierte er noch am selben Tag sichtlich gereizt nach Paris, daß es sich bei diesem Vorschlag des französischen Ministers um ein Mißverständnis ${ }^{17}$ handeln müsse: Wenn es sich um irgendeinen mäßigenden Druck in Petersburg handelt, so lebnen wir

13 Vgl. Bienvenu-Martin an Paul Cambon, Jules Cambon, Paléologue, Dumaine, Barrère, Bompard, 26. 7. 1914, in: DDF 3, 11, 98 und Schoen an AA, 26. 7. 1914, in: DD 1, 235.

14 Zit. Note pour le Ministre par intérim, 26. 7. 1914, in: DDF 3, 11, 109.

15 Zit. Note du Département, 26. 7. 1914, in: DDF 3, 11, 110.

$16 \mathrm{Vgl}$. das Telegramm des Justizministers vom 27. Juli, in dem er seine Reaktion auf die Demarchen des deutschen Botschafters begründete. Vgl. Bienvenu-Martin an Jules Cambon, Paléologue und Paul Cambon, 27. 7. 1914, in: DDF 3, 11, 133. Vgl. ferner die Einlassungen des Justizministers gegenüber dem russischen Botschafter. Vgl. Iswolski an Sasonow, 27. 7. 1914, in: IB I/5 129. Zur Abwandlung des Kommuniques vgl. auch Bertie an Grey, 27. 7. 1914, in: BD 11, 184.

$17 \mathrm{Zit}$. Sasonow an Iswolski und Benckendorff, 27. 7. 1914, in: IB I/5 116. 
diesen von vornherein $a b^{18}$. Um ein Mißverständnis handelt es sich dann auch in der Tat, denn es konnte keine Rede davon sein, daß Frankreich im Sinne der deutschen Forderung nach einer Lokalisierung des Konfliktes auf das Zarenreich einwirken und dieses auffordern würde, in einem Krieg der Habsburgermonarchie gegen Serbien nicht zu intervenieren. In einem Telegramm vom 28. Juli bestätigte der französische Außenminister ausdrücklich die Absage, die sein Stellvertreter dem deutschen Botschafter zuvor auf ein solches Ansinnen erteilt hatte ${ }^{19}$. Auch den moderaten Kräften im französischen Kabinett, dem Ministerpräsidenten und seinem Justizminister, war hier in ihrem Handeln eine Grenze gezogen, die sie für den Erhalt des Friedens nicht zu überschreiten bereit waren. Als der unermüdliche deutsche Botschafter am 27. Juli abermals versuchte, Frankreich im Sinne der deutschen Forderungen zu einem mäßigenden Einwirken auf das Zarenreich zu veranlassen, scheiterte dieser Versuch umgehend ${ }^{20}$.

Nach seiner Rückkehr nach Paris am 27. Juli konnte dann der russische Botschafter seinem Außenminister folglich nicht zu unrecht mitteilen: $\ddot{U} b e r-$ haupt war ich hier überrascht, wie richtig der Justizminister und seine Mitarbeiter die Situation erfassen, und wie sebr sie von der festen und rubigen Entschlossenbeit durchdrungen sind, uns vollste Unterstützung zu gewäbren und den geringsten Schein einer Meinungsverschiedenbeit mit uns zu vermei$d^{21}{ }^{21}$. Diese umfassende Unterstützung des Bündnispartners, von der der russische Botschafter nach Petersburg berichtete, bestand nicht nur darin, daß sich Frankreich der Forderung widersetzte, im Sinne des Deutschen Reiches auf Rußland einzuwirken, sondern fand darüber hinaus auch ihren konkreten Ausdruck in der Behandlung, die der erste Vermittlungsversuch Großbritanniens durch das französische Außenministerium erfuhr.

Der britische Außenminister sah sich in der Julikrise mit einer verfahrenen Situation, letztlich gar mit dem "central dilemma of British foreign policy " konfrontiert, das der britische Historiker Michael Ekstein einmal mit den Worten formuliert hat: »how to secure the understandings with France and Russia without upsetting Germany ${ }^{22}$ und das sich in der internationalen

\section{Zit. ibid.}

19 Vgl. Viviani an Bienvenu-Martin, 28. 7. 1914, in: DDF 3, 11, 190: J'approuve pleinement la réponse que vous avez faite au baron de Schoen.

$20 \mathrm{Zu}$ den Demarchen des deutschen Botschafters vom 27. Juli vgl. Bienvenu-Martin an Jules Cambon, Paléologue, Paul Cambon, 27. 7. 1914, in: DDF 3, 113 sowie Ferry an Paul Cambon und Jules Cambon, 27. 7. 1914, in: DDF 3, 11, 151. In seinen Telegrammen an das Auswärtige Amt hat der Botschafter diese Schritte nicht mehr erwähnt. Vgl. deshalb seine Darstellung in: Eduard Wilhelm von SCHOEN, Erlebtes. Beiträge zur politischen Geschichte der neuesten Zeit, Stuttgart, Berlin 1921, S. 168-170.

$21 \mathrm{Zit}$. Iswolski an Sasonow, 27. 7. 1914, in: IB I/5 129. Am darauffolgenden Tag telegraphierte Iswolski dann: Wie aus meiner gestrigen Unterredung am Quai d'Orsay bervorgebt, [hat] der Justizminister keinen Augenblick die Möglichkeit einer mäßigenden Einwirkung in Petersburg zugegeben. Zit. Ders. an Dens., 28. 7. 1914, in: IB I/5 177. 22 Zit. EksTEIN, Great Britain, S. 342. 
Gefahrensituation des Juli 1914 in der Frage zusammenzog, ob es unter den gegebenen Umständen möglich sein würde, das Deutsche Reich zu einem mäßigenden Einfluß auf seinen Bündnispartner zu veranlassen, ohne aber gleichzeitig durch eine Politik, die dem Deutschen Reich seine Grenzen aufzeigte, Frankreich und Rußland zu einer harten Haltung zu ermutigen ${ }^{23}$.

Im Rahmen dieser Untersuchung ist bereits deutlich geworden, daß in den letzten Jahren vor Ausbruch des Großen Krieges nicht allein maßgebliche Entscheidungsträger Frankreichs, sondern mit dem Botschafter Buchanan und Militärattaché Knox, dem permanenten Unterstaatssekretär Nicholson und Außenminister Grey zahlreiche Repräsentanten britischer Außenpolitik von einer fast ungeheuer anmutenden Machtentfaltung Rußlands überzeugt waren. Beruhte doch auch ihr Machtbegriff nicht primär auf der Kraft des Ökonomischen, sondern auf geographischen, demographischen und militärischen Elementen ${ }^{24}$.

Den Entscheidungsträgern Frankreichs ganz ähnlich zogen auch die Diplomaten und Außenpolitiker Großbritanniens aus ihren Beobachtungen die Schlußfolgerung, daß das Zarenreich in absehbarer Zeit in einem solchen Maße an Macht zulegen würde, das es ihm möglicherweise erlauben konnte, unabhängig von britischer Unterstützung zu handeln ${ }^{25}$. Die Machtentfaltung Rußlands mußte dabei um so bedeutungsvoller erscheinen, als nach Ansicht zahlreicher außenpolitischer Repräsentanten Großbritanniens die imperialen Positionen ihres Landes im Mittleren und Fernen Osten und insbesondere in Indien in nicht unbeträchtlichen Maße vom russischen Wohlwollen abhängig waren ${ }^{26}$. Buchanan zog aus der russischen Machtentfaltung die Schlußfolgerung, that we must retain her [gemeint ist Rußland, St. S.] friendship at almost any $\operatorname{cost}^{27}$, und sein Urteil bewegte sich damit in denselben Bahnen, in denen auch der permanente Unterstaatssekretär im Foreign Office dachte, der noch in der Julikrise einen Bericht der britischen Botschaft in Paris mit der Anno-

23 Vgl. Niall Ferguson, Pity of War, London 1999, S. 155.

${ }^{24}$ Zur britischen Wahrnehmung der russischen Machtentfaltung vgl. ROPPONEN, Kraft, S. 285-289; WOHLFORTH, Perception 355-358 und insbesondere NEILSON, Steamroller. Vgl. auch STEINER, NeILSON, Britain and the Origins, S. 114 f.; Dies., Foreign Office and Foreign Policy, 1898-1914, Cambridge 1969, S. 136f. und NeILsON, Britain and the Last Tsar, S. 136-140.

$25 \mathrm{Vgl}$. Buchanan an Grey, 18. 3. 1914, in: BD 10/2, 528: Even without the co-operation of England, Russia and France combined will then be strong enough to confront the united forces of the Triple Alliance.

26 Vgl. Buchanan an Nicolson, 16. 4. 1914, in: BD 10/2, 538 und Nicolson an Cartwright, 19. 2. 1913, in: BD 9/2, 632; Ders. an Buchanan, 22. 10. 1912, in: BD 9/2, 67 und insbesondere Ders. an Goschen, 18. 5. 1914, in: BD 10/2, 510: I am quite sure that if we broke away from Russia [...] we should bitterly rue the day. Russia would be able to make herself exceedingly disagreeable to us in regions where we are unfortunately very weak. Aus der Forschungsliteratur vgl. Edward INGRAM, In defense of British India: Great Britain in the Middle East, 1775-1842, London 1984, passim und WILSON, Policy of Entente, S. $76 \mathrm{f}$.

27 Zit. Buchanan an Nicolson, 16. 4. 1914, in: BD 10/2, 538. 
tation versah: Russia is a formidable Power and will become increasingly strong. Let us hope our relations with her will continue to be friendly ${ }^{28}$. Aus der Sicht Buchanans und Nicolsons galt es, die Entente mit Rußland schon allein deshalb nicht zu gefährden, da in ihr eine der besten Rückversicherungen gegen einen deutsch-russischen Ausgleich lag, der Großbritannien nicht allein in Asien mit einer aktiven russischen Politik, sondern darüber hinaus auf dem europäischen Kontinent mit einer übermächtigen Kombination konfrontiert hätte.

Mag rückblickend auch die Sorge vor einer deutsch-russischen Verständigung als »absurde Furcht ${ }^{2} 29$ beurteilt worden sein - insbesondere dem britischen Botschafter in Petersburg und dem permanenten Unterstaatssekretär, in geringerem $\mathrm{Maße}$ aber auch Grey, stand sie doch als Möglichkeit vor $\mathrm{Au}-$ gen $^{30}$. In europäischer Perspektive gilt es ferner zu berücksichtigen, daß Buchanan, Nicolson und auch der innerhalb des Foreign Office als Deutschland-Experte geltende Sir Eyre Crowe in den Bindungen an Frankreich und Rußland den besten Schutz gegen das Deutsche Reich erblickten. Insbesondere der Assistant Under-Secretary war davon überzeugt, daß das Deutsche Reich ein highly dangerous ${ }^{31}$ Gegner sei, und sah es nach der Hegemonie in Europa streben ${ }^{32}$. Insgesamt betrachtet hätte der genannte Personenkreis aufgrund dieser Überlegungen die britischen Bindungen an Frankreich und Rußland am liebsten in Allianzen umgewandelt gesehen ${ }^{33}$, und selbst für Grey, der nicht zu sehr in das russische Fahrwasser geraten wollte und für den eine Allianz mit Frankreich oder dem Zarenreich out of question ${ }^{34}$ war,

28 Zit. Annotation Nicolsons zu Granville an Grey, 18. 7. 1914, in: BD 11, 66.

29 Zit. NeITZEL, Kriegsausbruch, S. 159.

30 Faktoren ganz unterschiedlicher Provenienz ließen in den letzten Monaten vor Kriegsausbruch insbesondere Nicolson über die Möglichkeit einer solchen Verständigung nachdenken. Aus der umfangreichen Korrespondenz zu dieser Frage vgl. vor allem seinen Vermerk zu Buchanan an Grey, 18. 3. 1914, in: BD 10/2, 528; Nicolson an Goschen, 30. 3. 1914, in: BD 10/2, 533 und Ders. an de Bunsen, 30. 3. 1914, in: NL Nicolson, PRO, FO 800/373, fol. 40f. Für Buchanan vgl. Buchanan an Nicolson, 16. 4. 1914 , in: BD 10/2, 538 .

31 Zit. Randbemerkung Crowes zu: Goschen an Grey, 10. 2. 1914, in: BD 10/2, 501.

$32 \mathrm{Vgl}$. Crowes Memorandum vom 14.1. 1912, in: BD 7, Appendix III. Vgl. ferner seine Annotation zu: Bertie an Grey, 3. 4. 1912, in: BD 6, 564. Vgl. ferner STEINER, Foreign Office, S. 140-147. Zum Bild, das sich Nicolson vom Deutschen Reich machte, vgl. insbesondere: Keith NEILson, "My beloved Russia«. Sir Arthur Nicolson and Russia, 1906-1916, in: International History Review 9 (1987), S. 521-554, hier S. 553.

33 Mit bemerkenswerter Offenheit sprachen sich Nicolson und Crowe über diesen Gegenstand mehrfach gegenüber dem Leiter der Operationsabteilung im britischen Stab aus. Für Nicolson vgl. beispielsweise NL WILSON, Diaries, IWM, DS/MISC/80, fol. 125 (Eintrag vom 4. Mai 1912); für Crowe vgl. ibid., fol. 122 (Eintrag vom 1.5. 1912) und fol. 129 (Eintrag vom 8. Mai 1912): Crowe tells me tonight that Grey is at last alarmed + waking up + Crowe also insists on the necessity of an alliance. Grey seems to be coming to believe [Lesart unsicher] this but says such a slip would break up the cabinet. So best.

34 Zit. Grey an Bertie, 1. 5. 1914, in: BD 10/2, 541. 
standen eine Beeinträchtigung oder gar ein Rückzug aus der russischen Entente nicht zur Disposition ${ }^{35}$. Aus all diesen Gründen erschien Großbritannien ein harter machtpolitischer Druck auf das Zarenreich ausgeschlossen zu sein, den man erzeugen konnte, indem man Frankreich und Rußland eindeutig zu verstehen gab, daß ein Krieg der Habsburgermonarchie gegen Serbien die britischen Interessen nicht berühren und folglich kein Grund für eine militärische Intervention auf dem Kontinent bestehen würde ${ }^{36}$. Was unter den gegebenen Umständen verblieb, war die Option einer machtpolitischen Pression auf das Deutsche Reich: die Erklärung, daß eine militärische Auseinandersetzung Großbritannien an der Seite Frankreichs und Rußland finden würde.

$\mathrm{Daß}$ der britische Außenminister sich nicht schon zu Beginn der Julikrise zu einem solchen Handeln durchringen konnte, hat ihm nicht nur die scharfen Angriffe seiner Zeitgenossen, gar das Verdikt Lloyd Georges, Grey sei one of the two men primarily responsible for war ${ }^{37}$, sondern mitunter auch die Kritik der Historiker eingetragen ${ }^{38}$. Nicht genügend Berücksichtigung findet in diesem Zusammenhang jedoch vielleicht, daß insbesondere das Deutschlandbild des Außenministers sich deutlich von dem jener "antideutschen Phalanx « im Foreign Office unterschied ${ }^{39}$. So hatten sich nach der letzten Krise um das marokkanische Sultanat die britisch-deutschen Beziehungen merklich entspannt ${ }^{40}$, und Außenminister Grey war im Herbst 1913 der

35 Vgl. KiessLing, Entspannung, S. 230; STEINER, Foreign Office, S. 151 f. und FerguSON, Pity of War, S. 72.

36 Die Bedeutung des russischen Faktors und damit der britischen Interessen in Asien für das Handeln des Außenministers hat Keith Wilson in einer Reihe von Untersuchungen zum Gegenstand betont. Seiner Ansicht nach unterlag der britischen Außenpolitik auch in der Julikrise 1914 »an imperial scale of priorities « und »Grey's personal decision for war cannot be understood and appreciated fully if this background is not taken into account «. Zit. Keith M. WILSON, Britain, in: DERS. (Hg.), Decisions for War, 1914, New York 1995, S. 175-208, hier S. 186. Vgl. auch WILSON, Policy of Entente, S. 78.

${ }^{37}$ Zit. The Political Diaries of Charles P. Scott, 1911-1928. Hg. von Trevor WILSON, London 1970, S. 328 (Eintrag vom 7./8. 1. 1918). Vgl. auch David LLOYD GEORGE, War memoirs, Bd. I, Boston 1933, S. 57. Vgl. auch John Charmely, Splendid isolation? Britain, the Balance of Power and the Origins of the First World War, London 1999, S. 175 f., 331-333.

38 Vgl. David Calleo, The German Problem Reconsidered: Germany and the World Order, 1870 to the Present, Cambridge 1978, S. 6 und Donald Kagan, On the Origins of War and the Preservation of Peace, New York, London, Toronto 1995, S. 206.

39 Zit. DülfFer, Vermiedene Kriege, S. 626. Auch das Bild, das sich der Privatsekretär des britischen Außenministers, Wihelm Tyrell, vom Deutschen Reich machte, unterschied sich deutlich von dem des genannten Personenkreises. Zu seiner außenpolitischen Gedankenbildung vgl. Michael EksteIN, The Development of British War Aims, August 1914-March 1915, Diss. London 1969, S. 87-94 und STEINER, Foreign Office, S. 147-152. Der Einfluß Tyrells auf den Außenminster wird in der historischen Forschung kontrovers diskutiert. Vgl. EKSTEIN, Development, S. 87 und, den Einfluß des Privatsekretär geringer veranschlagend, STEINER, Foreign Office, S. $151 \mathrm{f}$.

40 Vgl. KiEsSLING, Entspannung, S. 95-108, 224-235. 
Auffassung: For the last year the policy of Germany had been unaggressive; she tried to smooth over difficulties and not to create them. This I believed to be the sincere policy of the German Chancellor and the Secretary for Foreign Affairs ${ }^{41}$. Noch im Juni 1914 vertraute er seinem Botschafter in Frankreich an, that the German Government are in a peaceful mood and they are very anxious to be on good terms with England ${ }^{42}$. Dem britischen Außenminister waren gute deutsch-britische Beziehungen - so ist unlängst in der historischen Forschung konstatiert worden - ein genuines Ziel seiner Politik ${ }^{43}$, und dies nicht zuletzt auch deshalb, weil er in einer zu weitgehenden Bindung seines Landes an Frankreich oder Rußland das Risiko erblickte, auf dem europäischen Kontinent in eine militärische Auseinandersetzung verwickelt zu werden, in der Großbritanniens Interessen nicht auf dem Spiel standen ${ }^{44}$.

Aus diesen Gründen entschied sich Grey im Juli 1914 zunächst gegen eine eindeutige Positionsbestimmung, glaubte er doch, damit auf beide kontinentalen Lager mäßigend einwirken und sich ihnen gleichsam als ehrlicher Makler anbieten zu können ${ }^{45}$. In diesem Sinne unterschied der britische Außenminister am 24. Juli zwischen einem österreichisch-serbischen Konflikt, in den Großbritannien nicht zu intervenieren beabsichtigte, da er die British Interests nicht berührte, und einer österreichisch-russischen Auseinandersetzung, die den Frieden Europas bedrohte, und in der Großbritannien zu vermitteln bemüht war. Der britische Außenminister schlug deshalb vor, daß die vier "nicht-interessierten " Mächte - das Deutsche Reich, Großbritannien, Frankreich und Italien - im letztgenannten Konflikt vermittelnd zwischen der Habsburgermonarchie und dem Zarenreich tätig werden sollten ${ }^{46}$. In der historischen Forschung ist mitunter die Ansicht vertreten worden, daß dieser Vermittlungsversuch Großbritanniens darauf hinausgelaufen wäre, Österreich-Ungarn freie Hand gegen Serbien zu gewähren, Rußland an einer militärischen Intervention zu hindern und damit im deutschen Sinne den Krieg auf dem Balkan zu lokalisieren ${ }^{47}$. Doch dies entsprach nicht den Absichten

41 Zit. Grey an Rennie, 15. 9. 1913, in: PRO, FO 371/1754, fol. 128. Vgl. auch EKSTEIN, Development, S. $93 \mathrm{f}$.

42 Zit. Memorandum, 27. 6. 1914, in: NL Bertie, PRO, FO 371/171.

${ }^{43}$ Vgl. KIESSLING, Entspannung, S. $229 \mathrm{f}$.

44 Vgl. NeILSON, Britain and the Last Tsar, S. $334 \mathrm{f}$.

${ }^{45} \mathrm{Daß}$ dieser Kurs Greys der Ausdruck einer bewußt getroffenen Entscheidung und nicht die ihm angesichts einer innenpolitischen $Z$ wangslage einzig verbliebende Möglichkeit war, läßt die Unterredung erkennen, die er am 29. Juli mit dem deutschen Botschafter führte. Obwohl am 29. Juli sein Unterfangen mißlang, die Zustimmung des Kabinetts zu einer Intervention zu erhalten, gab er Lichnowsky an diesem Tag zu verstehen, daß Großbritannien im Fall einer Eskalation der Krise nicht neutral bleiben könne. Zur Unterredung vom 29. Juli vgl. Lichnowsky an AA, 29. 7. 1914, in: DD 2, 357 und Ders. an Dass., 29. 7. 1914, in: DD 2, 368. Vgl. auch STEINER, NEILSON, Britain and the Origins, S. $239 \mathrm{f}$. und WILSON, Britain, S. 187-190.

$46 \mathrm{Vgl}$. hierzu insbesondere Lichnowsky an AA, 24. 7. 1914, in: DD 1, 157 und Grey an Buchanan, 24. 7. 1914, in: BD 11, 112.

47 Vgl. Albertini, Origins, Bd. II, S. 343. 
des britischen Außenministers. Sein Vermittlungsversuch vom 24. Juli enthielt im Kern einen Vorschlag, den er dann im weiteren Fortgang der Krise den Mächten noch einmal unterbreiten sollte und der vorsah, nach einer begrenzten Okkupation des serbischen Territoriums durch die Habsburgermonarchie eine Vermittlung einzuleiten. I had thought, erläuterte der AuBenminister dem britischen Botschafter in Paris seine Gedanken, that if Austria did move into Servia, and Russia then mobilised, it would be possible for the four Powers to urge Austria to stop her advance, and Russia also to stop hers, pending mediation ${ }^{48}$. Sicherlich: Greys Bemühen trug den Realitäten der militärischen Planungen keine Rechnung und mußte deshalb zum Scheitern verurteilt $\operatorname{sein}^{49}$. Da der deutsche Feldzugsplan auf einer langsamen russischen Mobilmachung basierte, mußte diese am Beginn eines Automatismus stehen, der überall in Europa zu Mobilmachung und Krieg führen würde. Doch dessen ungeachtet erlaubt dieses britische Vermittlungsbemühen, das der Habsburgermonarchie einen begrenzten militärischen Erfolg und die Ergreifung territorialer Pfänder gestattete, die Grenzen der französischen Konzessionsbereitschaft näher zu bestimmen.

Der französische Botschafter in London, der nach der Bekanntgabe des Ultimatums sofort den russischen Botschafter konsultiert hatte, lehnte in seiner ersten Unterredung mit dem britischen Außenminister ein solchermaßen gefaßtes Vermittlungsbemühen umgehend $a b$ und sprach sich statt dessen dafür aus, daß das Deutsche Reich eine Vermittlung der vier »nicht-interessierten « Mächte zwischen Serbien und Österreich-Ungarn vorschlagen solle, deren unausgesprochene Voraussetzung in einem Aufschub aller militärischen Operationen bestand 50 . Doch der Außenminister beharrte entgegen der Hoffnungen Paul Cambons auf seinem Vermittlungsversuch und ließ diesen in Paris förmlich unterbreiten ${ }^{51}$. Damit sah sich Frankreich am 25. Juli mit einem Angebot konfrontiert, das ihm mit Rücksicht auf seinen russischen Bündnispartner nicht annehmbar war, das es jedoch mit Blick auf die Haltung Großbritanniens im Fall einer Eskalation der Krise eindeutig abzulehnen vermied. Frankreich behandelte deshalb den Vorschlag Großbritanniens ausweichend und wartete den weiteren Fortgang der Dinge ab. Erst am

48 Zit. Grey an Bertie, 24. 7. 1914, in: BD 11, 98.

49 Insbesondere Albertini hat dies zu einer harschen Kritik am britischen Außenminister veranlaßt. Vgl. ALBERTINI, Origins, Bd. II, S. 334-345.

50 Vgl. Paul Cambon an Bienvenu-Martin, 24. 7. 1914, in: DDF 3, 11, 23. Zur Reaktion Benckendorffs vgl. Benckendorff an Sasonow, 25.7. 1914, in: IB I/5 54 und Grey an Buchanan, 25. 7. 1914, in: BD 11, 132.

51 Vgl. Grey an Bertie, 24. 7. 1914, in: BD 11, 98 und Note de l'Ambassade de GrandeBretagne, 25. 7. 1914, in: DDF 3, 11, 48. Vgl. ferner die Telegramme des britischen AuBenministers an seine Botschafter in Sankt Petersburg und Berlin, in denen er das Vermittlungsangebot erläuterte und die in Kopie auch an Bertie gesandt wurden. Vgl. Grey an Buchanan, 25. 7. 1914, in: BD 11, 112 und Ders. an Rumbold, 25. 7. 1914, in: BD 11, 116. 
27. Juli erteilte das Außenministerium am Quai d'Orsay dem britischen Botschafter eine sehr vorsichtig formulierte, im Kern ablehnende Antwort ${ }^{52}$, nahm aber im Gegenzug den zweiten britischen Vermittlungsvorschlag an, der ihm am 26. Juli unterbreitet worden war und auf den gleich in anderem Zusammenhang zurückzukommen sein wird ${ }^{53}$.

Als das erste britische Vermittlungsangebot der französischen Führung am späten Abend des 27. Juli an Bord der »France « bekannt wurde ${ }^{54}$, kam es innerhalb der französischen Führung zu einem offenen Konflikt zwischen dem Präsidenten und dem Ministerpräsidenten. Poincaré reagierte auf das Verhandlungsangebot sehr erbost:

Pourquoi [médiation] entre l'Autriche et la Russie? La Russie n'a rien dit et elle n'a pas bougé; elle n'est jusqu'ici aucunement mêlée au conflit. En revanche, va-t-on laisser l'Autriche en tête à tête avec la Serbie? La Serbie parait aussi avoir cédé sur tous les points de l'ultimatum, sauf sur deux, qu'elle a, disent les télégrammes, réservés: sans doute, le désaveu officiel et l'enquête mixte. Mais si l'Autriche veut pousser plus loin sa victoire, si elle déclare la guerre ou si elle entre à Belgrade, l'Europe laissera-t-elle faire? Et est-ce entre l'Autriche et la Russie qu'elle cherchera seulement à mettre le bolà? Ça serait, en réalité, prendre partie pour l'Autriche, qui aurait le champ libre de côté serbe $e^{5}$.

Poincaré forderte seinen Außenminister umgehend auf, diese Einwände an den britischen Außenminister weiterzuleiten, was zu tun Viviani sich jedoch weigerte: J'expose toutes ces objections à Viviani, qui jusqu'ici cependant ne juge pas à propos de les formuler à Londres ${ }^{56}$. In diesem Verhalten erblickte der französische Präsident nur einen weiteren Beweis für die außerordentliche Ignoranz seines Außenministers ${ }^{57}$. Deutlich ließ das erste britische Vermittlungsbemühen die Bruchlinien innerhalb der französischen Führung sichtbar werden.

$52 \mathrm{Vgl}$. die Antwortnote des französischen Außenministeriums in: Bertie an Grey, 27. 7. 1914, in: BD 11, 194. Dort heißt es in Bezug auf das erste britische Vermittlungsbemühen: Le Ministre des Affaires Étrangères par intérim a l'bonneur de faire connaître à son Excellence Sir Francis Bertie qu'il a invité $M$. Jules Cambon à se concerter avec l'Ambassadeur d'Angleterre en Allemagne et à appuyer la démarche qu'ils jugeront opportune de faire auprès du Cabinet de Berlin. Dies war offensichtlich keine direkte Antwort auf das britische Ansinnen. Entsprechende Instruktionen hat das französische Außenministerium an seinen Botschafter in Berlin deshalb nie gesandt. Vgl. auch Note verbale pour l'ambassade de Grande-Bretagne, 27. 7. 1914, in: DDF 3, 11, 164.

53 Zum zweiten britischen Vermittlungsvorschlag vgl. Grey an Bertie, 26. 7. 1914, in: BD 11, 140 und Ders. an Dens., 26. 7. 1914, in: BD 11, 143. Vgl. ferner Bertie an Grey, 27. 7. 1914, in: BD 11, 183.

54 Es ist im zweiten Teil des sehr langen Telegramms enthalten, das der Justizminister am 26. Juli über die französische Botschaft in Kopenhagen an den Außenminister sandte. Vgl. Bienvenu-Martin an Paul Cambon, Jules Cambon, Paléologue, Barrère, Dumaine und Bapst, 26. 7. 1914, in: DDF 3, 11, 90.

55 Zit. Notes journalières, in: NL Poincaré, BNF, Nafr. 16027, fol. 121 (Eintrag vom 27. 7. 1914).

56 Zit. ibid.

57 Vgl. Notes journalières, in: NL Poincaré, BNF, Nafr. 16027, fol. 122 (Eintrag vom 27.7. 1914). 
Der Ministerpräsident, der Paléologue am 23. Juli mit den Worten angefahren hatte: Nous nous en floutons] de la Serbie ${ }^{58}$, war offensichtlich dazu bereit, im Interesse eines friedlichen Ausgleichs unter den Großmächten Konzessionen zu Lasten Serbiens zu machen, der Habsburgermonarchie einen begrenzten militärischen Erfolg zu gestatten und sich damit partiell vom Zarenreich zu distanzieren. Doch Poincarés eindringlich vorgetragene Einwände waren letztlich nicht vergeblich. Am 28. Juli, nachdem auch der französischen Führung der zweite Vermittlungsversuch Großbritanniens bekannt geworden war ${ }^{59}$, sandte Viviani ein Telegramm an das französische Außenministerium, das in Inhalt und Diktion unverkennbar die Signatur des Präsidenten trug. Mit ihm lehnte er nun ausdrücklich jede Vermittlung zwischen der Habsburgermonarchie und dem Zarenreich ab, die nicht unter der Voraussetzung stand, daß Österreich-Ungarn sich zuvor dazu verpflichtete, sich eines militärischen Angriffs gegen seinen südöstlichen Nachbarn zu enthalten, und nahm im Gegenzug den zweiten britischen Vermittlungsvorschlag an ${ }^{60}$.

Dieser zweite Vermittlungsvorschlag war am 26. Juli von Nicolson in Reaktion auf ein Telegramm des britischen Botschafters in Petersburg entworfen worden, das am späten Abend des 25. Juli in London eingetroffen war ${ }^{61}$. Mit diesem Telegramm hatte Buchanan mitgeteilt, daß Paléologue dem russischen Außenminister in ihrer gemeinsamen Unterredung zugesichert hatte, that France placed berself unreservedly on Russia's side, und daß dieser daraufhin zur Antwort gab: Russia cannot allow Austria to crush Servia and become predominant Power in the Balkans, and secure of support of France, she will face all the risks of war62. Schon als am 24. Juli ein Telegramm Buchanans eingetroffen war, das von einer ähnlichen Einlassung des französischen Botschafters berichtete, hatte Crowe dieses mit der Annotation versehen: The moment has passed when it might bave been possible to enlist French support in an effort to hold back Russia ${ }^{63}$, und dieses Urteil wurde noch durch den Umstand bestätigt, daß der britische Außenminister bislang keine Antwort Frankreichs auf sein erstes Vermittlungsbemühen erhalten hatte.

Die entschlossene Haltung Frankreichs zeitigte nun einen ersten Erfolg für die Mächte der französisch-russischen Allianz, denn Grey ließ am 26. Juli in Paris, Petersburg und Berlin förmlich den Vorschlag unterbreiten, daß eine Botschafter-Konferenz, die sich aus den Botschaftern der vier »nicht-interessierten « Mächte zusammensetzen würde, zwischen der Habsburgermonar-

58 Zit. undatierte Notiz Doulcets über ein Gespräch mit Paléologue, in: NL Doulcet, MAE, PA-AP 240/23, fol. 100.

$59 \mathrm{Vgl}$. Notes journalières, in: NL Poincaré, BNF, Nafr. 16027, fol. 122 (Eintrag vom 28. 7. 1914).

60 Vgl. Viviani an Bienvenu-Martin, 28. 7. 1914, in: DDF 3, 11, 190.

61 Vgl. Nicolson an Grey, 26. 7. 1914, in: BD 11, 139.

62 Zit. Buchanan an Grey, 25. 7. 1914, in: BD 11, 125.

63 Zit. Ders. an Dens., 24. 7. 1914, in: BD 11, 101. 
chie, Serbien und dem Zarenreich vermitteln solle. Im Gegensatz zu seinem Vorschlag vom 24. Juli sollte diese Konferenz unter der Voraussetzung stehen, daß die drei letztgenannten Mächte mit keiner militärischen Operation beginnen würden, Österreich-Ungarn folglich nicht zur militärischen Invasion seines südöstlichen Nachbarn schritt ${ }^{64}$.

Doch diesen Vermittlungsvorschlag lehnte nun das Deutsche Reich umgehend ab. Theobald von Bethmann Hollweg telegraphierte am 27. Juli nach London, daß er der Auffassung sei, daß man, mit Rücksicht auf das Prestige und den Großmachtstatus des Bündnispartners, Österreich in seinem Serbenbandel nicht vor ein europäisches Gericht zieben könne ${ }^{65}$. Entscheidend für diese Haltung war wohl, daß durch eine internationale Konferenz zur Schlichtung des Streits dem Deutschen Reich sein diplomatischer Triumph, auf den es so kühn spekuliert hatte, abhanden kommen würde. Denn eine Vermittlung zwischen der Habsburgermonarchie, Serbien und dem Zarenreich, die unter der am 26. Juli vom britischen Außenminister gemachten Voraussetzung stand, lief letztlich auf eine Vermittlung zwischen ÖsterreichUngarn und Serbien hinaus, die der französische Botschafter in London dem britischen Außenminister bereits am 24. Juli suggeriert hatte ${ }^{66}$.

$\mathrm{Da}$ die Voraussetzungen, unter denen die Londoner Botschafterkonferenz stehen würde, sich für Frankreichs Interessen günstig ausnahmen, konnten das Außenministerium am Quai d'Orsay und die französische Führung an Bord der "France « diesem Vermittlungsbemühen Großbritanniens zustimmen ${ }^{67}$. Zum einen würde sich das mit den Mittelmächten nicht allzu fest verbündete Italien aufgrund seiner Interessen auf dem Balkan wohl kaum dazu bereit finden, Serbien in eine Abhängigkeit von der Habsburgermonarchie geraten zu lassen, zum anderen mußte während der Verhandlungen durch die russische Mobilmachung auf dem Deutschen Reich ein übermächtiger Druck lasten. Denn auch dieser zweite britische Vermittlungsvorschlag stand nicht unter der Bedingung, daß das Zarenreich und Österreich-Ungarn sich während der Phase der Verhandlungen jeder Mobilmachung enthielten ${ }^{68}$. Eine begrenzte diplomatische Niederlage Serbiens, nicht aber ein grundlegender und dauerhafter Wandel des Status quo auf dem Balkan oder gar ein begrenzter militärischer Erfolg der Habsburgermonarchie gegen Serbien - auf dieser Basis war Frankreich im Juli 1914 zu einem friedlichen Ausgleich bereit.

$64 \mathrm{Vgl}$. Note de l'Ambassade de Grande-Bretagne, 26. 7. 1914, in: DDF 3, 11, 107.

65 Zit. Bethmann Hollweg an Lichnowsky, 27. 7. 1914, in: DD 1, 247.

66 Vgl. Paul Cambon an Bienvenu-Martin, 24. 7. 1914, in: DDF 3, 11, 23.

67 Vgl. Bienvenu-Martin an Fleuriau, 27.7.1914, in: DDF 3, 11, 123 und Note verbale pour l'ambassade de Grande-Bretagne, 27. 7. 1914, in: DDF 3, 11, 164. Vgl. ferner Viviani an Bienvenu-Martin, 28. 7. 1914, in: DDF 3, 11, 190 und Ders. an Paul Cambon, 28. 7. 1914, in: DDF 3,11, 193.

${ }^{68}$ Ausdrücklich hieß es im Vorschlag des britischen Außenministers: to request those Governements to suspend all active military operations pending the results of the Conference. Zit. Note de l'Ambassade de Grand-Bretagne, 26. 7. 1914, in: DDF 3, 11, 107. 
Von der Idee einer Vermittlung der vier »nicht-interessierten« Mächte zwischen Österreich-Ungarn und dem Zarenreich, nicht aber Serbien, hatte der russische Außenminister zuerst durch ein Telegramm seines Botschafters in London am 25. Juli erfahren ${ }^{69}$. Benckendorff hatte gegen ein solches Vermittlungsbemühen umgehend Einwände erhoben, doch der britische Außenminister hatte diese nicht gelten lassen, und für Rußland stand nun zu befürchten, daß es sich bald mit einer förmlichen Anfrage Großbritanniens konfrontiert sehen würde ${ }^{70}$. Unter diesen Umständen griff Sasonow einen Gedanken des deutschen Botschafters auf, der ihm am 26. Juli empfohlen hatte, direkte Verhandlungen mit Österreich-Ungarn zu führen ${ }^{71}$.

In seiner Unterredung mit dem Außenminister des Zaren fand der Botschafter der Habsburgermonarchie diesen am 26. Juli zu seiner ersichtlichen Überraschung vollkommen gewandelt ${ }^{72}$. Für die Slawen auf dem Balkan, so ließ sich der russische Außenminister nunmehr vernehmen, empfinde er gar keine Sympathie. Diese seien für Rußland sogar eine schwere Last und wir könnten uns kaum vorstellen, was man von ibnen schon zu leiden gebabt habe. Die Absicht der Habsburgermonarchie, sich gegen die Dekomposition ihres Reiches zu schützen, war ihm nun ein vollkommen legitimes Ziel, und nur das mit dem Ultimatum in dieser Hinsicht verwandte Mittel schien ihm nicht glücklich zu sein. $\mathrm{Da}$ es sich eigentlich in der Notenangelegenheit nur um Worte, nicht aber um einen wirklichen Interessensgegensatz handle, unterbreitete Sasonow Szápáry den Vorschlag, mit ihm in direkte Verhandlungen einzutreten, die nach seiner Ansicht zu einer Modifikation des Ultimatums führen sollten ${ }^{73}$.

In der historischen Forschung ist mitunter die These vertreten worden, daß der Versuch des russischen Außenministers, eine unmittelbare Verständigung mit der Habsburgermonarchie herbeizuführen, ein »außerordentlich bedeutender Schritt « in Richtung auf den Erhalt des Friedens gewesen sei, der von einer »aufrichtigen Absicht« getragen wurde ${ }^{74}$. Doch scheint dies unwahrscheinlich zu sein. Am 24. Juli war Sasonow zu der Überzeugung gelangt, daß die Habsburgermonarchie mit ihrem Ultimatum einen Krieg gegen ihren südöstlichen Nachbarn einzuleiten beabsichtigte und daß das Deutsche Reich seinem Bündnispartner uneingeschränkte Unterstützung gewährte. Im Rahmen der entscheidenden Ministerratssitzung hatte er am 24. Juli ausgeführt: the information at his disposal and his knowledge of events in Central

$69 \mathrm{Vgl}$. Benckendorff an Sasonow, 25. 7. 1914, in: IB I/5 54.

70 Zur Unterredung zwischen dem britischen Außenminister und dem russischen Botschafter vgl. ibid. Vgl. ferner Grey an Buchanan, 25. 7. 1914, in: BD 11, 132.

$71 \mathrm{Vgl}$. Friedrich POURTALES, Meine letzten Verhandlungen in St. Petersburg Ende Juli 1914. Tagesaufzeichnungen und Dokumente, Berlin 1927, S. $22 \mathrm{f}$.

72 Vgl. auch Pourtalès an AA, 26. 7. 1914, in: DD 1, 238.

73 Zit. Szápáry an Berchtold, 27. 7. 1914, in: ÖUA 8, 10835. In diesem Sinne telegraphierte auch Sasonow am 26. Juli an seinen Botschafter in Wien. Vgl. Sasonow an Schebeko, 26. 7. 1914, in: IB I/5 86.

74 Vgl. insbesondere SCHMITT, Coming of War, Bd. II, S. $24 \mathrm{f}$. 
Europe during the past years had convinced him that Austro-Hungary and Germany were resolved to deal a decisive blow at Russian authority in the Balkans by annibilating Serbia, und bis zum 26. Juli hatte er keine Nachrichten erhalten, die ihn dazu veranlassen konnten, an diesem Urteil zu zweifeln ${ }^{75}$. Angesichts dieser Umstände hat der französische Historiker Isaac sicherlich nicht Unrecht, wenn er in den Worten des russischen Außenministers vom 26. Juli "une part de comédie «76 erblickt. Die direkten Verhandlungen mit der Habsburgermonarchie gestatteten es dem Außenminister aber, zwei Dinge zu tun: Zum einen konnte es ihm durch Gespräche, deren Scheitern ihm als wahrscheinlich galt, gelingen, Österreich-Ungarn ins Unrecht zu setzen, zum anderen würden es ihm die direkten Verhandlungen mit der Habsburgermonarchie möglich machen, mißliche Vermittlungsbemühungen Großbritanniens ausweichend zu behandeln, ohne aber den Eindruck entstehen zu lassen, daß das Zarenreich sich einem friedlichen Ausgleich widersetzte. Am 27. Juli nutzte er dann die direkten Verhandlungen mit der Habsburgermonarchie, um das zweite britische Vermittlungsbemühen, hinter dem er immer noch einen Versuch der mäßigenden Einflußnahme Großbritanniens zum Nachteil russischer Interessen argwöhnte, dilatorisch zu behandeln ${ }^{77}$. Zwar nahm er den Vorschlag des britischen Außenministers im Prinzip an, ließ aber wissen, daß er zunächst den Ausgang seiner Gespräche mit dem Botschafter Österreich-Ungarns abwarten wolle ${ }^{78}$.

Das französische Außenministerium wurde durch diesen Schritt des $\mathrm{Za}$ renreiches sichtlich irritiert. Fürchtete es doch, daß die Habsburgermonarchie die direkten Verhandlungen dazu nutzen könnte, in der Zwischenzeit durch eine Invasion Serbiens Tatsachen zu schaffen. Dieses würde aber nichts anderes bedeuten, als daß son avantage diplomatique se double d'un succès militaire qui lui permettrait d'imposer à la Serbie, sous le nom élastique de garanties, des conditions qui modifieraient, en fait, [...] le statut de l'Europe orientale $^{79}$. Doch Österreich-Ungarn setzte den direkten Verhandlungen bald selbst ein Ende. Am 28. Juli lehnte sein Außenminister in einer Unterredung mit dem russischen Botschafter jede Revision der österreichischen Note $a b^{80}$, und auch das Deutsche Reich trachtete nicht danach, einen Druck auf seinen Bündnispartner auszuüben, um die Gespräche zwischen der Habsburgermonarchie und Rußland zu einem Erfolg zu führen. Zwar telegraphierte Bethmann Hollweg am 27. Juli nach London, daß er die direkten

75 Vgl. Bark's Memoirs, in: NL Bark, Rare Book and Manuscript Library. Columbia University, $1 / 7$, S. 12 f.

$76 \mathrm{Zit}$. IsAAC, Un débat historique, S. 135.

77 Vgl. Sasonow an Iswolski und Benckendorff, 27. 7. 1914, in: IB I/5 116.

78 Vgl. ibid.

79 Zit. Runderlaß des Justizministers vom 29. Juli, in: DDF 3, 11, 246. Vgl. auch die Aufzeichnung Abel Ferrys vom 28./29. Juli, in: DDF 3, 11, 255.

80 Vgl. die dem russischen Botschafter vom Außenminister der Habsburgermonarchie erteilte Antwort. Vgl. Schebeko an Sasonow, 28. 7. 1914, in: IB I/5 188. 
Verhandlungen zwischen beiden Mächten fördere ${ }^{81}$, doch zur gleichen Zeit bat er die Habsburgermonarchie ausschließlich um ihre "Ansicht « über die begonnenen Gespräche ${ }^{82}$.

Erst als sich in Folge der Kriegserklärung Österreich-Ungarns an Serbien, der Bombardierung Belgrads und der russischen Teilmobilmachung die Lage dramatisch zuspitzte, schien dem deutschen Reichskanzler der Augenblick gekommen zu sein, im gemeinschaftlichen Zusammenwirken mit Großbritannien einen Weg aus der Krise zu finden. Erst zu diesem Zeitpunkt griff er eine Anregung des deutschen Kaisers auf, der nach der Lektüre der dem Ultimatum entgegenkommenden serbischen Antwortnote jeden Grund für einen Krieg hatte wegfallen sehen und infolgedessen am 28. Juli den Vorschlag eines "Halt in Belgrad " gemacht hatte ${ }^{83}$. Doch die Interventionen des Reichskanzlers in Wien, die sich am 30. Juli zu der Drohung steigerten, daß es das Deutsche Reich ablehnen müsse, sich von seinem Bündnispartner in einen Weltbrand ${ }^{84}$ hineinziehen zu lassen, zeitigten keine Erfolge mehr. Die Habsburgermonarchie weigerte sich einfach, den einmal begonnenen Krieg gegen Serbien einzustellen. Auch den Interventionsversuchen des britischen Außenministers, der am 30. Juli in Paris und Petersburg den Gedanken eines "Halt in Belgrad " zur Annahme empfahl, war kein Erfolg mehr beschieden ${ }^{85}$. Zwar nahmen Rußland und Frankreich den britischen Vermittlungsvorschlag am 31. Juli an ${ }^{86}$, doch war innerhalb der französischen Führung wohl nur Viviani tatsächlich dazu bereit, auf dieser Basis einen friedlichen Ausgleich zwischen den Mächten herzustellen. Noch am 30. Juli hatte der russische Botschafter in London einen begrenzten Einmarsch der Habsburgermonarchie in Serbien abgelehnt ${ }^{87}$, und der Außenminister des Zaren sollte dem britischen Vermittlungsbemühen erst in dem Bewußtsein zustimmen, $\mathrm{da} ß$ die am 30. Juli befohlene russische Generalmobilmachung einer friedlichen Lösung des Konfliktes die letzte Aussicht auf Erfolg genommen hatte8 ${ }^{88}$

$81 \mathrm{Vgl}$. Bethmann Hollweg an Lichnowsky, 27. 7. 1914, in: DD 1, 248.

82 Vgl. Bethmann Hollweg an Tschirschky, 27. 7. 1914, in: DD 2, 277.

83 Vgl. Wilhelm II. an Jagow, 28. 7. 1914, in: DD 2, 293.

84 Zit. Bethmann Hollweg an Tschirschky, 30. 7. 1914, in: DD 2, 396. Vgl. auch Ders. an Dens., 28.7. und 30. 7. 1914, in: DD 2, 384 und 396.

85 Vgl. Lichnowsky an AA, 29. 7. 1914, in: DD 2, 357 und Ders. an Dass., 29. 7. 1914, in: DD 2, 368. Vgl. auch den nicht mehr abgesandten Entwurf eines Telegramms des britischen Außenministers an seinen Botschafter in Berlin. Vgl. Grey an Goschen, 29. 7. 1914, in: BD 11, 285. Vgl. ferner Greys Telegramme an Buchanan und Bertie vom 30. Juli. Vgl. Grey an Buchanan, 30. 7. 1914, in: BD 11, 309 und Ders. an Bertie, 30. 7. 1914, in: BD 11, 310.

86 Vgl. Buchanan an Grey, 31. 7. 1914, in: BD 11, 393 und Viviani an Paléologue, 31. 7. 1914, in: DDF 3, 11, 405.

$87 \mathrm{Vgl}$. Benckendorff an Sasonow, 30. 7. 1914, in: IB I/5 286. Nach seiner Unterredung mit dem russischen Botschafter telegraphierte Paul Cambon nach Paris: Je ne crois pas que la Russie donne son adbésion à cette proposition. Zit. Paul Cambon an Viviani, 30. 7. 1914, in: DDF 3, 11, 363.

88 Nach langen Auseinandersetzungen zwischen dem Außenminister und dem Gene- 
Um durch einen Druck auf die Habsburgermonarchie und das Zarenreich eine Verhandlung auf der Grundlage einer begrenzten Okkupation Serbiens einzuleiten, hätte es einer gewissen Zeit bedurft. Doch diese stand für die kontinentalen Mächte in der Endphase der Julikrise aufgrund von Feldzugsplänen, die im Zeichen der unbedingten Offensive entworfen worden waren, nicht zur Verfügung.

Bevor es im einzelnen zu bestimmen gilt, welchen Anteil Frankreich in den letzten Tagen der Krise daran hatte, den fatalen Mechanismus der Mobilmachungen auszulösen, soll zunächst noch betrachtet werden, wie sich die innenpolitischen Bedingungen seiner äußeren Politik in der Spanne zwischen dem 28. Juni und dem 29./30. Juli ausnahmen.

\section{Die Stimmungslage in der französischen Bevölkerung}

Da ein Krieg im 20. Jahrhundert einem Existenzkampf der Nationen gleichen und damit im Gegensatz zum Krieg der Kabinette des 18. Jahrhunderts nach einer die gesamte Bevölkerung umfassenden, nationalen Anstrengung verlangen würde, war die Stimmungslage der Öffentlichkeit zu einem Faktor geworden, der die Erfolgschancen eines Staates in einer militärischen Auseinandersetzung in ganz erheblichem Maße beeinflussen mußte. Für alle Mächte war deshalb die geschlossene und uneingeschränkte Unterstützung durch die eigene Bevölkerung im Fall eines Krieges von zentraler Bedeutung.

Die französische Führung war davon überzeugt, daß es ihr nach Lage der Dinge im Juli 1914 nur unter ganz bestimmten Bedingungen möglich sein würde, einen Krieg mit der uneingeschränkten Zustimmung durch die eigene Bevölkerung zu führen. Nach ihrer Einschätzung waren die Franzosen weder dazu bereit, einen Krieg für die Souveränität Serbiens zu führen, noch würde ein Krieg, der allein aus Verpflichtungen gegenüber dem russischen Bündnispartner erwuchs, ungeteilte Zustimmung finden. J'ai toujours cru, so notierte der Präsident unter dem Datum des 5. Januar 1915 rückblickend in seinem Tagebuch, que les Français ne voudraient pas déclarer la guerre pour la Serbie. J'ai même cru que la France ne se lèverait pas toute entière pour tenir envers la Russie les promesses de l'alliance et que, si nous étions amenés à déclarer la guerre, le pays serait [unleserliches Wort] divisé. Mais je n'ai jamais douté de la France pour le cas où elle serait attaquée, fût-ce à propos de la Serbie ${ }^{89}$.

ralstabschef auf der einen, dem russischen Monarchen auf der anderen Seite, war der Befehl zur Generalmobilmachung am 30. Juli um $16 \mathrm{Uhr}$ ergangen. Vgl. hierzu die Ausführungen im Abschnitt "Der russische Entscheidungsprozeß«.

89 Zit. Notes journalières, in: NL Poincaré, BNF, Nafr. 16029, fol. 7 (Eintrag vom 5. 1. 1915). Bereits im Frühjahr 1914 hatte der französische Präsident dem britischen Außenminister eingestanden, daß im Fall eines deutschen Angriffs auf Rußland die Bevölkerung seines Landes der Regierung nicht geschlossen in einen Krieg folgen würde. 
Für die französische Staatsführung zog sich damit, was die innenpolitischen Bedingungen ihrer außenpolitischen Entscheidungen betraf, alles in der Frage zusammen, ob es ihr gelingen würde, im Fall einer Eskalation der Krise das Deutsche Reich ins Unrecht zu setzen. Nur unter dieser Voraussetzung würde es ihr möglich sein, die Bevölkerung - und mit ihr auch die Sozialisten - für eine Unterstützung des Krieges zu gewinnen, und nur unter diesen Umständen konnte sie dann auch hoffen, ohne Rekurs auf staatliche Zwangsmaßnahmen einen gewissen Einfluß auf die Entscheidungen der in der Confédération générale du travail organisierten Gewerkschaften auszuüben, die in den Jahren vor Ausbruch des Weltkrieges von 1914 mehrfach dazu aufgerufen hatten, die französische Generalmobilmachung ungeachtet ihres internationalen Kontextes mit Generalstreik und revolutionärer Insurrektion zu beantworten ${ }^{90}$.

Vor diesem Hintergrund werden zwei Dinge ersichtlich: Zum einen tritt, was die Frage des Handlungsspielraums der französischen Führung im Juli 1914 betrifft, hervor, daß Poincaré und Paléologue, als sie am 23. und 24. Juli dem Zarenreich den uneingeschränkten Beistand Frankreichs zusicherten, einen außenpolitischen Kurs einschlugen, dessen Richtung ihnen nicht durch eine Stimmungslage in der französischen Öffentlichkeit vorbestimmt war. Ganz im Gegenteil waren der französische Präsident und sein Botschafter davon überzeugt, daß die Bevölkerung nur widerstrebend die Einsicht in das nach ihrer Auffassung außenpolitisch Notwendige vollziehen und die damit gegebenenfalls verbundenen Konsequenzen tragen würde. Zum anderen wird vor dem Hintergrund dieser Einschätzung auch deutlich, daß die $\mathrm{Zu}-$ stimmung Frankreichs zu den unterschiedlichen Bemühungen um einen friedlichen Ausgleich in den Fällen, in denen ihr ein taktisches Kalkül unterlag, nicht allein von der Absicht getragen wurde, eine rasche militärische Intervention Großbritanniens herbeizuführen, sondern daß sie zugleich mit Blick auf die Stimmungslage in der französischen Öffentlichkeit erfolgte.

Um auf deren Krisenwahrnehmung einzuwirken, entfaltete die französische Diplomatie jedoch nicht nur in den Verhandlungen mit den anderen Mächten ihr taktisches Geschick. Darüber hinaus versuchten im Zeitraum

Vgl. Grey an Bertie, 1. 5. 1914, in: BD 10/2, 541. Der kommissarische Leiter des AuBenministeriums gestand dem britischen Botschafter am 25. Juli 1914, that it would be difficult to bring French public opinion to fighting point in such a case as present one. Zit. Bertie an Grey, 25. 7. 1914, in: BD 11, 129.

90 Zur Haltung des Parti socialiste vgl. insbesondere Jack D. ELLIS, French Socialists and the Problem of Peace 1904-1914, Chicago 1967 und Georges LEFrANC, Le mouvement socialiste sous la Troisième République, Bd. I: De 1875 à 1919, Paris 1967. Zur Haltung der Gewerkschaften vgl. Annie KRIEGEL, Patrie ou révolution: le mouvement ouvrier français devant la guerre (juillet-aôut 1914), in: Revue d'histoire économique et sociale 18 (1965), S. 363-386; Jean JUSSERAND, La C. G. T. devant la guerre (1900-1914), in: Le mouvement social 49 (1964), S. 47-62 und Peter W. REUTER, Gewerkschaften, Antimilitarismus und staatliche Gegenstrategien in Frankreich vor dem Ersten Weltkrieg, in: Francia 10 (1982), S. 390-428. 
zwischen dem 24. und dem 28./29. Juli die Staatsführung, der Ministerrat und das Außenministerium auch unmittelbar, die öffentliche Meinung Frankreichs zu beeinflussen.

$\mathrm{Zu}$ den Schritten, die in diesem Sinne erfolgten, zählen zum einen der am 25. Juli gefaßte Entschluß der französischen Führung, zunächst nicht frühzeitig nach Paris zurückzukehren ${ }^{91}$, und zum anderen der Versuch des Kabinetts, die militärischen Maßnahmen, die seit dem 24. Juli in Frankreich eingeleitet wurden, sorgfältig geheimzuhalten ${ }^{92}$. Beide Entscheidungen waren darauf gerichtet, den Eindruck zu vermeiden, daß Frankreich sich auf eine militärische Intervention vorbereite, um nicht vorzeitig eine Reaktion der Sozialisten und Gewerkschaften hervorzurufen ${ }^{93}$. Darüber hinaus versuchte das Außenministerium aber auch bereits zu einem sehr frühen Zeitpunkt, der französischen Öffentlichkeit die Verantwortlichkeit des Deutschen Reiches für die gegenwärtige internationale Krise darzulegen.

Infolge der auf ein fait accompli gerichteten Außenpolitik des Deutschen Reiches und der Habsburgermonarchie hatte die Ermordung des österreichungarischen Thronfolgers in der französischen Öffentlichkeit zunächst nur geringe Beachtung gefunden. Raymond Recouly, der im Juli 1914 als Redakteur für den "Figaro" arbeitete, sollte später das Interesse, das man in Frankreich in der Spanne zwischen dem 28. Juni und dem 23. Juli dem Attentat und seinen möglichen internationalen Folgen entgegen gebracht hatte, mit der

91 Vgl. Notes journalières, in: NL Poincaré, BNF, Nafr. 16027, fol. 115 (Eintrag vom 25. 7. 1914): Revenir? Ce serait effrayer l'opinion française et européenne, et laisser supposer que la France peut [Lesart unsicher] se mêler au conflit. Auch Paléologue äußerte am 24. Juli gegenüber dem Kanzleidirektor des russischen Außenministeriums die Auffassung, daß es das Beste sei, wenn die französische Führung ihre Reise zunächst fortsetze. Vgl. Tagesaufzeichnung des russischen Außenministeriums, 24. 7. 1914, in: IB I/ 525 .

92 Der letztgenannte Schritt entsprach auch den Regeln der militärischen Geheimhaltung, die den Gegner über Art und Umfang der getroffenen Maßnahmen im Unklaren zu lassen suchte. Aber damit ist seine gesamte Bedeutung noch nicht umfassend beschrieben. Das Telegramm, mit dem die Präfekten aufgefordert wurden, die Presse zu überwachen, vermerkt ausdrücklich: Il faut éviter soigneusement toutes mesures ostensibles qui seraient de nature à inquiéter l'opinion publique. Archivdokument. Zit. nach: Jean-Jacues BECKER, 1914: Comment les Français sont entrés dans la guerre, Paris 1977, S. 143. Die Bemühungen der Präfekten waren zweifellos effektiv. Was die militärischen Maßnahmen Frankreichs anging, bemerkte Jules Isaac rückblickend: „De la France ..., mais de la France nous n'avons presque rien su en 1914 (si ce n'est le recul de dix kilomètres)«. Zit. IsAAC, Ce que nous avons su, S. 300. Auf die Entscheidung des Kabinetts, die französischen Truppen zehn Kilometer von der deutschen Grenze zurückzuziehen, wird noch in anderem Zusammenhang ausführlich einzugehen sein.

93 Vgl. BECKER, 1914: Comment les Français sont entrés dans la guerre, S. 142-144 und DERS., L'opinion française a-t-elle eu une influence sur la politique extérieure de la France lors de la crise de juillet 1914?, in: Opinion publique et politique extérieure. Colloque organisé par l'École française de Rome et le Centro per gli studi di politica estera e opinione publica de l'université de Milan, Bd. I, Mailand, Paris 1981, S. 207222, hier S. $220 \mathrm{f}$. 
Wirkung eines très gros fait divers ${ }^{94}$ vergleichen, und vor dem kritischen Blick der historischen Forschung hat dieses Urteil noch immer Bestand 95 .

Als dann am 24. Juli das Ultimatum der Habsburgermonarchie der überraschten Presse bekannt wurde, verurteilte sie es scharf ${ }^{96}$. Doch hinsichtlich der Frage, welchen Anteil das Deutsche Reich am Zustandekommen der österreich-ungarischen Forderungen gehabt hatte, bestanden durchaus unterschiedliche Auffassungen. Zwar zeigte sich ein Teil der Presse schon zu einem sehr frühen Zeitpunkt davon überzeugt, daß das Deutsche Reich von den Absichten der Habsburgermonarchie in Kenntnis gesetzt worden sei und dem Ultimatum nicht nur zugestimmt, sondern es sogar gefordert habe; doch nicht selten ließ sich auch die Ansicht vernehmen, die deutsche Reichsleitung sei von ihrem Bündnispartner überrascht worden, befinde sich nun in einer sehr unangenehmen Lage und werde sicherlich versuchen, mäßigend auf die Habsburgermonarchie einzuwirken ${ }^{97}$.

Die in anderem Zusammenhang schon einmal erwähnte Demarche des deutschen Botschafters, der am 24. Juli das Außenministerium am Quai d'Orsay aufsuchte, die Forderungen der Habsburgermonarchie rechtfertigte und zur Lokalisierung des Konfliktes mahnte, wurde in dieser Situation zu einem wesentlichen Faktor für das Bild, das sich die französische Öffentlichkeit von den Absichten des deutschen Kaiserreichs machte ${ }^{98}$.

Durch einen ausführlichen Artikel im "Echo de Paris « wurden diese Ausführungen des deutschen Botschafters am 25. Juli der Öffentlichkeit bekannt gemacht ${ }^{99}$. Das »Echo de Paris «, das die Ausführungen des Botschafters zum

94 Zit. ReCOUly, Les heures tragiques, S. 94: »Cet assassinat fit d'abord l'effet d'un très gros fait divers. Rien de plus. Pendant les deux ou trois semaines qui suivirent, cette impression, quoi qu'on en ait dit, ne se modifia point«.

95 Vgl. Eber Malcolm Carroll, French Public Opinion and Foreign Affairs. 18701914, New York, London 1931, S. 286f.; BECKER, 1914: Comment les Français sont entrés dans la guerre, S. 126-140 und insbesondere Thomas RAITHEL, Das »Wunder « der inneren Einheit. Studien zur deutschen und französischen Öffentlichkeit bei Beginn des Ersten Weltkrieges, Bonn 1996 (Pariser Historische Studien, 45), S. 147-171. Da die genannten Untersuchungen zu fast identischen Schlußfolgerungen gelangen, hat der Verfasser auf eine Auswertung der französischen Presseberichte verzichtet.

96 Vgl. Carroll, French Public Opinion, S. 286-288 und RaITHEL, Das "Wunder « der inneren Einheit, S. 176f. Der Geschäftsträger der russischen Botschaft telegraphierte am 25. Juli nach Petersburg: Die öffentliche Meinung und die Presse, ohne Unterschied der Richtungen, sind über sie [gemeint ist die Note der Habsburgermonarchie, St. S.] sebr empört. Zit. Sewastopulo an Sasonow, 25. 7. 1914, in: IB I/5 59. Vgl. auch die entsprechenden Beobachtungen des österreich-ungarischen und des deutschen Botschafters. Vgl. Szécsen, 25. 7. 1914, in: ÖUA 8, 10679 und Schoen an AA, 25. 7. 1914, in: DD $1,169$.

97 Vgl. BECKER, 1914: Comment les Français sont entrés dans la guerre, S. 140f. und RAITHEL, Das »Wunder« der inneren Einheit, S. 192.

$98 \mathrm{Vgl}$. insbesondere RAITHEL, Das »Wunder« der inneren Einheit, S. 192f. Ähnlich auch RECOULY, Les heures tragiques, $\mathrm{S}$. $99 \mathrm{f}$.

$99 \mathrm{Vgl}$. HERBETTE, La sommation autrichienne est suivie de la menace allemande, in: 
Teil richtig publizierte, zum Teil entstellte, erblickte in ihnen eine direkt gegen Frankreich gerichtete militärische Drohung und beurteilte vor diesem Hintergrund das Ultimatum Österreich-Ungarns als einen auf die Demütigung und den Ehrverlust Frankreichs gerichteten nouveau coup d'Agadir, der den Konflikt zwischen der Habsburgermonarchie und Serbien zu einem conflit diplomatique européen ${ }^{100}$ mache.

Der Artikel des "Echo de Paris « fand in der französischen Presse außerordentlich große Resonanz. Die Zeitungen der politischen Mitte brachten, angeführt vom einflußreichen "Le Temps «, ihre Empörung zum Ausdruck, und die extreme politische Rechte erblickte in den Einlassungen des deutschen Botschafters eine dem Ultimatum Österreich-Ungarns durchaus vergleichbare, nunmehr an die Adresse Frankreichs gerichtete Drohung ${ }^{101}$. Zwar versuchte der deutsche Botschafter umgehend, den eingetretenen Schaden zu begrenzen, und gewisse Erfolge seiner Bemühungen sind unverkennbar, doch die französische Öffentlichkeit ging infolge der Publikationen des »Echo de Paris« seit dem 25. Juli in zunehmendem Maße davon aus, daß das Deutsche Reich die Krise gezielt herbeigeführt habe und zu seinen Zwecken zu nutzen suche.

Obwohl der Artikel des "Echo de Paris « insbesondere in der Korrespondenz des britischen und des deutschen Botschafters ausführliche Beachtung fand ${ }^{102}$, hat die historische Forschung ihn zumeist nur am Rande erwähnt ${ }^{103}$. Es ist mitunter darüber spekuliert worden, ob dieser Artikel auf eine Inspiration durch die russische Botschaft zurückzuführen sei ${ }^{104}$, was angesichts der finanziellen Unterstützung, die dieses Blatt gelegentlich durch das Zarenreich erfuhr, nicht völlig von der Hand zu weisen ist ${ }^{105}$. Wahrscheinlicher ist jedoch, daß in der Abwesenheit des russischen Botschafters der Artikel des "Echo de Paris « seinen Ursprung in einer gezielten Aktion des französischen Außenministeriums hatte, zumal sein Verfasser, Jean Herbette, in sehr engem

"L'Echo de Paris« vom 25. Juli 1914, S. 1. Das Blatt zählte mit einer Auflage von rund 150000 Exemplaren zu den größten Pariser Tageszeitungen.

100 Zit. ibid.

101 Vgl. RAITHEL, Das *Wunder « der inneren Einheit, S. $193 \mathrm{f}$.

102 Vgl. ibid. Vgl. ferner Bertic an Grey, 25. 7. 1914, in: BD 11, 123 und Ders. an Dens., 27. 7. 1914, in: BD 11, 193. Vgl. auch Sewastopulo an Sasonow, 25. 7.1914, in: IB I/5 59. 103 Zum ersten Mal erwähnt von CARROLL, French Public Opinion, S. 294. Becker geht auf diesen Schritt und seine Folgen nicht ein. Ausführlich untersucht wird der Artikel und seine Wirkung in: RAITHEL, Das »Wunder « der inneren Einheit, 192-197.

$104 \mathrm{Vgl}$. AlberTINI, Origins, Bd. II, S. 328. Auch die Vermutungen des britischen Botschafters führten in diese Richtung. Am 25. Juli telegraphierte er: The Echo de Paris is known to be in close relation with Russian Embassy. Zit. Bertie an Grey, 25. 7. 1914, in: BD 11, 123.

105 Zur Beeinflussung der französischen Presse durch das Zarenreich vgl. insbesondere TOMASZEWSKI, Triple Entente or Unholy Alliance, S. 240-251 und die ältere Darstellung Artur G. RafaloviC, L'abominable vénalité de la presse. D’après les documents des archives russes, 1897-1914, Paris 1931. 
Kontakt zum Quai d'Orsay stand ${ }^{106}$. Diese Umstände sprechen vielmehr dafür, daß der Artikel auf eine kalkulierte Indiskretion Berthelots zurückzuführen ist ${ }^{107}$, der bis zur Rückkehr Poincarés und Vivianis die Geschäfte des Ministeriums de facto führte.

Mit dem im »Echo de Paris« geschickt lancierten Artikel verfolgte er offensichtlich das Ziel, dem Konflikt zwischen der Habsburgermonarchie und dem Zarenreich eine deutsch-französische Dimension zu geben, die allein die französische Öffentlichkeit zu einer Intervention veranlassen konnte. Had the French public become convinced, telegraphierte der britische Botschafter, die Auswirkungen des Artikels wohl insgesamt unterschätzend, am 27. Juli nach London, that the action of $M$. de Schoen at the Quaid'Orsay was in the nature of a warning to France to remain quiet or to take the consequences, it is likely that great indignation would bave been aroused bere, and the task of those interested in stimulating French public opinion to range itself decidedly on the side of Russia in the present controversy would bave been facilitated ${ }^{108}$.

Damit wird jedoch deutlich, daß Berthelot nicht primär danach strebte, in der Öffentlichkeit ein Klima zu schaffen, das einen friedlichen Ausgleich der Mächte beförderte - denn unter diesen Umständen hätte er nicht einen Artikel angeregt, der die Einlassungen des deutschen Botschafters in eine Reihe mit der als demütigend empfundenen Verhandlungspraxis des Deutschen Reiches während der zweiten Marokkokrise stellte -, sondern daß er vor allem in innenpolitischer Hinsicht Frankreich in eine möglichst günstige Ausgangsposition für den Großen Krieg zu manövrieren suchte.

Der Eindruck, daß das Deutsche Reich die Krise eingeleitet habe und keinesfalls versuchen werde, mäßigend auf seinen Bündnispartner einzuwirken, wurde noch verstärkt, als die französische Öffentlichkeit erfuhr, daß sich Österreich-Ungarn von der serbischen Antwort auf sein Ultimatum, die in Frankreich am 26. Juli umgehend publiziert und von der Presse einstimmig als eine vollständige Annahme der Forderungen beurteilt worden war, nicht befriedigt gezeigt hatte ${ }^{109}$. Als zudem in den folgenden Tagen noch bekannt

106 Jean Herbette war der Cousin des Kabinettschefs des französischen Außenministers und arbeitete seit 1912 regelmäßig für die von Poincaré gegründete Zeitschrift »La Politique étrangère«. Zur Person Herbettes vgl. die Biographie: Yves DENÉCHÈRE, Jean Herbette (1878-1960). Journaliste et ambassadeur, Paris 2004.

107 In diese Richtung gingen auch die Vermutungen des deutschen Botschafters. Vgl. SCHOEN, Erlebtes, S. 167-169.

108 Zit. Bertie an Grey, 27. 7. 1914, in: BD 11, 193.

109 Während »Le Temps « bereits am 26. Juli ein »résumé exact« der serbischen Antwortnote publizierte, wurde im Deutschen Reich und in der Habsburgermonarchie die Antwort der serbischen Führung erst am 28. Juli bekannt, als sich Österreich-Ungarn bereits im Krieg mit seinem südöstlichen Nachbarn befand. Vgl. RaITHEL, Das »Wunder « der inneren Einheit, S. 180f. Der Botschafter der Habsburgermonarchie in Paris telegraphierte am 26. Juli an sein Außenministerium, daß die Zurückweisung der serbischen Antwort allgemein unangenehmen Eindruck mache. Zit. Szécsen an Berchtold, 26. 7. 1914, in: ÖUA 8, 10742. Vgl. auch Ders. an Dens., 27. 7. 1914, in: ÖUA 8, 10822. 
wurde, daß das Deutsche Reich den britischen Vorschlag abgelehnt habe, daß die vier "nicht-interessierten " Mächte in Petersburg, Wien und Belgrad vermittelnd tätig werden sollten, zeigte sich die französische Presse davon überzeugt, daß das Kaiserreich die Eskalation der Krise gezielt betreibe ${ }^{110}$. Der Anlaß der Krise, das die staatliche Souveränität mißachtende Ultimatum, hatte damit für die französische Öffentlichkeit an Bedeutung verloren. Das Deutsche Reich trat drohend in den Vordergrund, und in seinem übermächtigen, alles verdunkelnden Schatten verschwanden nicht nur die Habsburgermonarchie und ihr südöstlicher Nachbar, sondern zugleich auch das Zarenreich ${ }^{111}$. Frankreich schien in den Augen der französischen Öffentlichkeit nicht durch sein Bündnis mit Rußland, sondern durch das drohend auftretende Deutsche Reich in einen Krieg gestoßen zu werden, den zu verhindern, so die übereinstimmende Überzeugung, die französische Führung nichts unversucht gelassen hatte ${ }^{112}$.

Dieser Auffassung schlossen sich am 28. und 29. Juli auch die sozialistische Partei und die Gewerkschaften an. Es ist hier nicht zu untersuchen, welche Gründe dafür maßgeblich wurden, daß im Juli 1914 das Band zwischen dem Individuum und der Nation sich letztlich als sehr viel belastbarer als das Band zwischen dem einzelnen und seiner gesellschaftlichen Klasse herausstellte. Festzuhalten ist nur, daß Fraktion und Parteiführung der französischen Sozialisten am 28. Juli eine Resolution publizierten, in der sie der Regierung ihr Vertrauen aussprachen, und daß dieser Erklärung am 29. Juli ein Manifest der Confédération générale du travail folgte, mit dem sich die $\mathrm{Ge}-$ werkschaftsführung indirekt von ihren früheren Aufrufen zum Generalstreik distanzierte und den auf den friedlichen Ausgleich gerichteten Bemühungen der französischen Führung die Unterstützung des Peuple français zusicherte ${ }^{113}$. Die syndikalistischen und sozialistischen Veranstaltungen, die insbesondere im Zeitraum zwischen dem 27. und 30. Juli stattfanden und deren politische Aussage sich zumeist auf die Rufe »Vive la paix! « und " $A$ bas la guerre! « beschränkte, hatten folglich nach der Auffassung ihrer Organisa-

\section{$110 \mathrm{Vgl}$. RAITHEL, Das "Wunder« der inneren Einheit, S. $198 \mathrm{f}$.}

111 Die Frage, ob den Bündnisverpflichtungen gegenüber dem Zarenreich nachzukommen sei, wurde von der Presse seit dem 28./29. Juli nicht mehr diskutiert. Der russische Botschafter in Paris telegraphierte am 29. Juli an Sasonow: Was die Solidarität mit uns betrifft, so wird diese Frage als völlig eindeutige Tatsache gar nicht erst eingebend erörtert. In diesem Sinne äußern sich alle Journalisten, darunter so prominente Persönlichkeiten [...], wie Pichon, Clemenceau und sogar Jaurès und der Initiator des Antimilitarismus Hervé. Zit. Iswolski an Sasonow, 29. 7. 1914, in: IB I/5 232.

112 Vgl. BECKER, 1914: Comment les Français sont entrés dans la guerre, S. 579f. und RAITHEL, Das »Wunder « der inneren Einheit, S. $197 \mathrm{f}$.

113 Zum Entscheidungsprozeß innerhalb der sozialistischen Partei und der Gewerkschaftsführung vgl. BECKER, 1914: Comment les Français sont entrés dans la guerre, S. 190-238 und Annie KRIEGEL, Aux origines du communisme français 1914-1920. Contribution à l'histoire du mouvement ouvrier français, Paris, Bd. I, La Haye 1964, S. 52-61. 
toren nicht den Sinn, einen Druck auf die französische Regierung auszuüben, sondern diese in ihren Bemühungen um einen friedlichen Ausgleich zu unterstützen ${ }^{114}$.

Die nationalistischen Agitationsverbände Frankreichs entfalteten in der Julikrise nur eine sehr geringe Aktivität und erlegten sich bewußt große $\mathrm{Zu}-$ rückhaltung auf ${ }^{115}$. Auf ihrer zentralen Kundgebung anläßlich der Rückkehr der französischen Führung am 29. Juli ließen sich nur sehr vereinzelt die Rufe "A Berlin! « oder "À bas l'Allemagne" vernehmen"16.

Damit zeichnete sich in der Endphase der Julikrise für die französische Führung ab, daß eine der grundsätzlichen Voraussetzungen für eine erfolgreiche Kriegsführung gegeben sein würde. Nicht der geschlossenen und uneingeschränkten Zustimmung durch die Bevölkerung, sondern der unverzüglichen militärischen Intervention Großbritanniens sollte fortan ihr Bemühen gelten, und dies schien um so dringlicher geboten zu sein, als einem Teil der maßgeblichen Persönlichkeiten der große Krieg nunmehr unvermeidlich schien.

$114 \mathrm{Vgl}$. die prägnante Analyse in: BECKER, L'opinion française a-t-elle eu une influence sur la politique extérieure de la France lors de la crise de juillet 1914?, S. 210 f.

115 Am 27. Juli trug ein Informant der Préfecture de Police de Paris zu, daß auf einer Besprechung der Führer der Ligue des patriotes und der Action française beschlossen worden sei, daß ein massiver öffentlicher Protest erst einsetzen solle, falls sich abzeichne, daß die französische Führung ihren Bündnispflichten gegenüber dem Zarenreich nicht nachkomme. Frankreichs extreme Rechte fürchtete im Juli 1914, daß ihre Kundgebungen eine massive Reaktion der Sozialisten und Gewerkschaften hervorrufen würde. Vgl. BECKER, L'opinion française a-t-elle eu une influence sur la politique extérieure de la France lors de la crise de juillet 1914?, S. $213 \mathrm{f}$.

116 Vgl. Bertie an Grey, 29. 7. 1914, in: BD 11, 270. 